Article

\title{
Tricetin Induces Apoptosis of Human Leukemic HL-60 Cells through a Reactive Oxygen Species-Mediated c-Jun N-Terminal Kinase Activation Pathway
}

\author{
Ming-Hsien Chien ${ }^{1,2,+}$, Jyh-Ming Chow ${ }^{3,+}{ }^{,}$Wei-Jiunn Lee ${ }^{2,4}$, Hui-Yu Chen ${ }^{5}$, Peng Tan ${ }^{1}$, \\ Yu-Ching Wen ${ }^{4,6}$, Yung-Wei Lin ${ }^{1,6}$, Pei-Ching Hsiao ${ }^{7,8, *}$ and Shun-Fa Yang ${ }^{5,9, *}$ \\ 1 Graduate Institute of Clinical Medicine, College of Medicine, Taipei Medical University, Taipei 110, Taiwan; \\ mhchien1976@gmail.com (M.-H.C.); cancercute@yahoo.com.tw (P.T.); highwei168@gmail.com (Y.-W.L.) \\ 2 Department of Medical Education and Research, Wan Fang Hospital, Taipei Medical University, Taipei 116, \\ Taiwan; 1wj5905@gmail.com \\ 3 Division of Hematology and Medical Oncology, Department of Internal Medicine, Wan Fang Hospital, \\ Taipei Medical University, Taipei 116, Taiwan; chow0803@yahoo.com.tw \\ 4 Department of Urology, School of Medicine, Taipei Medical University, Taipei 110, Taiwan; \\ s811007@yahoo.com.tw \\ 5 Institute of Medicine, Chung Shan Medical University, Taichung 402, Taiwan; albee55@gmail.com \\ 6 Department of Urology, Wan Fang Hospital, Taipei Medical University, Taipei 116, Taiwan \\ 7 School of Medicine, Chung Shan Medical University, Taichung 402, Taiwan \\ 8 Department of Internal Medicine, Chung Shan Medical University Hospital, Taichung 402, Taiwan \\ 9 Department of Medical Research, Chung Shan Medical University Hospital, Taichung 402, Taiwan \\ * Correspondence: cshy046@csh.org.tw (P.-C.H.); ysf@csmu.edu.tw (S.-F.Y.); \\ Tel.: +886-4-2473-9595 (ext. 34712) (P.-C.H.); +886-4-2473-9595 (ext. 34253) (S.-F.Y.); \\ Fax: +886-4-2324-8171 (P.-C.H.); +886-4-2472-3229 (S.-F.Y.) \\ + These authors contributed equally to this work.
}

Received: 24 May 2017; Accepted: 25 July 2017; Published: 31 July 2017

\begin{abstract}
Tricetin is a dietary flavonoid with cytostatic properties and antimetastatic activities in various solid tumors. The anticancer effect of tricetin in nonsolid tumors remains unclear. Herein, the molecular mechanisms by which tricetin exerts its anticancer effects on acute myeloid leukemia (AML) cells were investigated. Results showed that tricetin inhibited cell viability in various types of AML cell lines. Tricetin induced morphological features of apoptosis such as chromatin condensation and phosphatidylserine (PS) externalization, and significantly activated proapoptotic signaling including caspase- $8,-9$, and -3 activation and poly(ADP-ribose) polymerase (PARP) cleavage in HL-60 AML cells. Of note, tricetin-induced cell growth inhibition was dramatically reversed by a pan caspase and caspase-8- and -9-specific inhibitors, suggesting that this compound mainly acts through a caspase-dependent pathway. Moreover, treatment of HL-60 cells with tricetin induced sustained activation of extracellular signal-regulated kinase (ERK) and c-Jun N-terminal kinase (JNK), and inhibition of ERK and JNK by their specific inhibitors respectively promoted and abolished tricetin-induced cell apoptosis. Dichlorofluorescein (DCF) staining showed that intracellular reactive oxygen species (ROS) levels were higher in tricetin-treated HL-60 cells compared to the control group. Moreover, an ROS scavenger, $\mathrm{N}$-acetylcysteine (NAC), reversed tricetin-induced JNK activation and subsequent cell apoptosis. In conclusion, our results indicated that tricetin induced cell death of leukemic HL-60 cells through induction of intracellular oxidative stress following activation of a JNK-mediated apoptosis pathway. A combination of tricetin and an ERK inhibitor may be a better strategy to enhance the anticancer activities of tricetin in AML.
\end{abstract}

Keywords: tricetin; apoptosis; c-Jun N-terminal kinase; reactive oxygen species; acute myeloid leukemia 


\section{Introduction}

Acute myeloid leukemia (AML) is a heterogeneous clonal disorder of hematopoietic progenitor cells and the most common type of leukemia in adults. Despite significant improvements being made in the past three decades in the understanding of leukemia pathogenesis, prognostic factors, drug treatment, and patient care procedures, the prognosis of AML is still not good enough, and estimated 5 -year overall survival after a standard chemotherapy is only $38 \%[1,2]$. Chemotherapy resistance and relapse still remain major challenges in treating AML [3]. Thus, a better understanding of the molecular biology of AML is needed, and alternative treatments for AML patients still need to be discovered.

Nowadays, some plant-derived natural products have been used as alternative treatments for leukemias including AML because of their extensive biological activities and comparatively low toxicities [4,5]. Tricetin (5,7,3', $4^{\prime}, 5^{\prime}$-pentahydroxyflavone), a dietary flavonoid in Myrtaceae pollen and Eucalyptus honey, appears to have potent anti-inflammatory properties which may be responsible for its beneficial effects [6]. Recently, tricetin has garnered much attention in relation to its anticancer activities such as antiproliferative and antimetastatic activities in many solid tumor cell models including breast [7], liver [8], lung [9], bone [10], and brain [11] tumors. Although it is quite clear that tricetin can inhibit the growth or metastasis of various solid tumor cells, the precise impact of tricetin on nonsolid tumors is still unclear.

Apoptosis is an active process of endogenous programmed cell death. The identified characteristics of apoptosis include morphologic changes such as condensation and fragmentation of nuclei, cell membrane shrinkage, and loosening of organelle positions in the cytoplasm. In addition to morphological changes, sophisticated molecular procedures and mechanisms are also involved. Apoptosis can be initiated either through a death receptor followed by caspase- 8 and -10 activation or the mitochondrial pathway involving caspase-9 [12]. One of the hallmarks of cancer is the deregulation of apoptosis; thus increasing apoptosis in tumors is one of the best ways for anticancer agents to treat all types of cancer. Actually, there are several plant-derived anticancer agents such as Vinca alkaloids, taxines, and podophyllotoxin already in clinical use [13].

The mitogen-activated protein kinase (MAPK) pathway is an important route that communicates extracellular signals in intracellular responses and was correlated with many physiological processes such as cell growth, differentiation, and apoptosis. In mammalian cells, there are three well-characterized subfamilies of MAPKs: extracellular signal-regulated kinases (ERKs), c-Jun N-terminal kinases (JNKs), and p38 MAPKs [14]. JNK was reported to be phosphorylated/activated after exposure of cells to stressful stimuli, such as irradiation and cancer chemotherapeutics, and it plays an important role in chemotherapeutic drug-mediated apoptosis [15]. Recently, it was reported that a JNK-activation defect confers chemoresistance in solid tumors such as ovarian and liver cancers [16,17]. Notably, involvement of the JNK-activation defect in anthracycline-containing chemotherapy resistance was also characterized in AML, and JNK targeting might be a new therapeutic approach for AML [18].

Although it is entirely clear about the anti-metastatic and anti-tumor growth effects of tricetin in various solid tumor cells, the exact impact of tricetin on nonsolid tumors is still unknown. This is the first study to determine the cell growth-inhibitory activity and molecular mechanisms of tricetin in different French-American-British (FAB) types of AML cells (THP-1, U937, HL-60, and MV4-11). Our results demonstrated that tricetin suppressed proliferation of these four AML cell lines. We found that superoxide was overproduced in HL-60 AML cells during tricetin treatment, which initiated a signal leading to activation of JNK-mediated apoptosis. Moreover, a combination of tricetin and an ERK inhibitor may be a better strategy than tricetin alone for treating AML. This study should provide a scientific basis for the clinical use of tricetin to effectively inhibit AML. 


\section{Results}

\subsection{Tricetin Inhibited Proliferation of Human Acute Myeloid Leukemia (AML) Cells}

The chemical structure of tricetin is shown in Figure 1A. In this study, we first examined the effect of tricetin on the growth of human AML cell lines using the cell counting kit-8 (CCK-8) assay. After treating cells with tricetin for $24 \mathrm{~h}$, the tricetin concentration dependently inhibited the proliferation of four AML cell lines which represent different FAB types (M2: HL-60 and M5: MV4-11, U937, and THP-1) (Figure 1B,C). Among these four AML cell lines, HL-60 cells were the most sensitive to tricetin treatment. Therefore, we chose HL-60 cells for subsequent experiments. We further studied the long-term antiproliferative potential of tricetin against HL-60 cells by trypan blue exclusion assay. As illustrated in Figure 1D, tricetin time- and concentration-dependently suppressed the growth of cultured HL-60 cells.

A<smiles>Oc1cc(O)c2c(c1)OC(c1cc(O)c(O)c(O)c1)C=C2</smiles>

$\mathrm{D}$

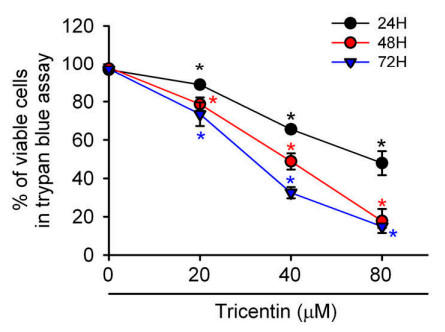

B

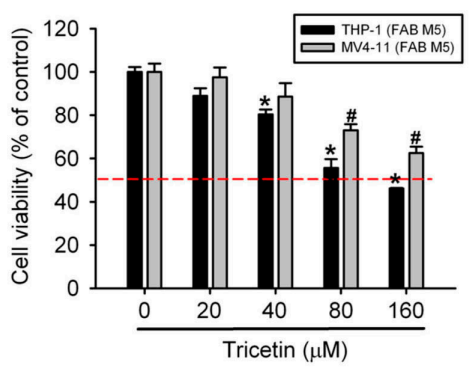

C

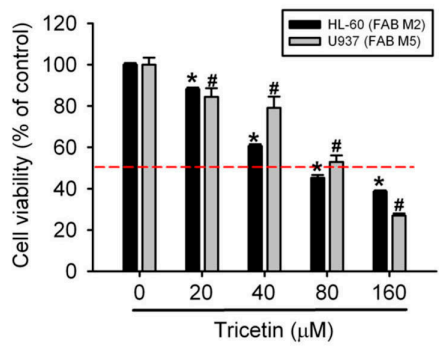

Figure 1. Tricetin treatment results in reduced cell viability of human acute myeloid leukemia (AML) cell lines. (A) The chemical structure of tricetin; (B,C) Four human AML cell lines (HL-60, U937, THP-1, and MV4-11) were treated with the vehicle (DMSO) or tricetin $(0 \sim 160 \mu \mathrm{M})$ in serum-containing medium for $24 \mathrm{~h}$; (D) HL-60 cells were treated with different concentrations of tricetin $(0 \sim 80 \mu \mathrm{M})$ for 24,48 , and $72 \mathrm{~h}$. Cell viability was determined by a trypan blue exclusion assay. Results are expressed as multiples of cell viability. Values represent the mean \pm standard error (SE) of three independent experiments. ${ }^{*},{ }^{*} p<0.05$, compared to the vehicle groups. The dashed line indicates $50 \%$ growth inhibition of cell viability.

\subsection{Tricetin Treatment Results in the Apoptosis of HL-60 AML Cells}

Physiological cell death is characterized by an apoptotic morphology, including cell shrinkage, nuclear condensation and fragmentation, translocation of phosphatidylserine (PS) to the extracellular membrane, dynamic membrane blebbing, and loss of adhesion to neighbors or to the extracellular matrix [19]. To determine whether tricetin-induced growth inhibition resulted from cell apoptosis, HL-60 cells were treated with tricetin $(0 \sim 80 \mu \mathrm{M})$ for $24 \mathrm{~h}$, and we found that tricetin induced concentration-dependent increases of the sub-G $\mathrm{G}_{1}$ population (Figure $2 \mathrm{~A}$ ). Moreover, we performed Annexin-V/PI double staining to identify translocation of PS in HL-60 cells. As shown in Figure 2B, early (PI-negative/Annexin-V-positive) and late apoptotic cells (PI-positive/Annexin-V-positive) all dramatically increased after respectively treating HL-60 cells with 40 and $80 \mu \mathrm{M}$ tricetin. Because the tricetin-induced increase in the PI-positive/Annexin-V-positive population also might have been due to induction of necrosis, we next examined the effect of tricetin on cell morphology by using fluorescence microscopy. Treatment of cells with $80 \mu \mathrm{M}$ tricetin for $24 \mathrm{~h}$ showed morphologies characteristic of apoptosis including chromatin condensation and apoptotic bodies 
formation (Figure 2C, arrows). These results are all hallmarks of cell apoptosis and confirmed that tricetin can induce apoptotic cell death in HL-60 cells.

A
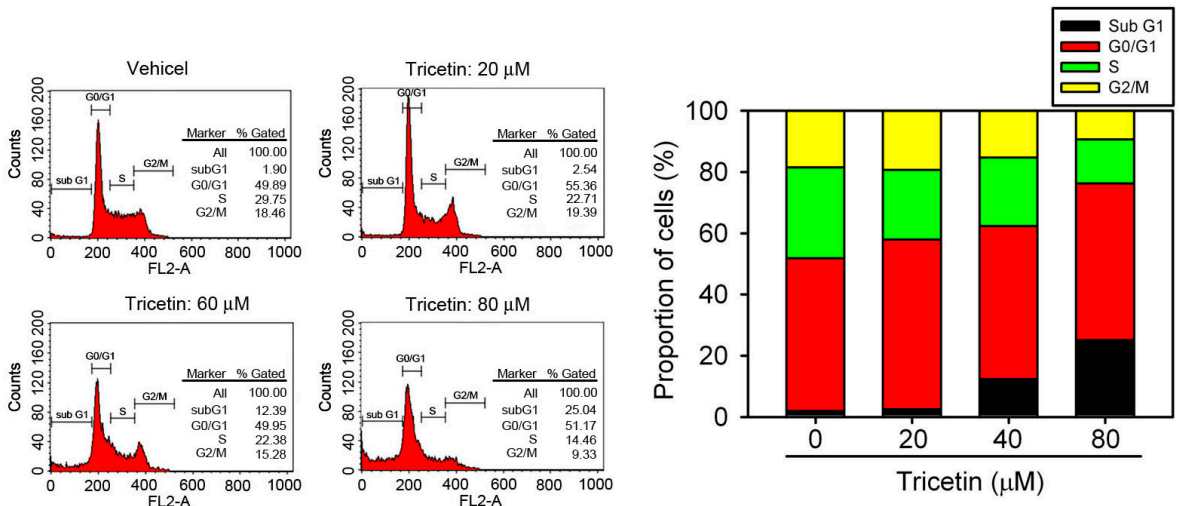

B
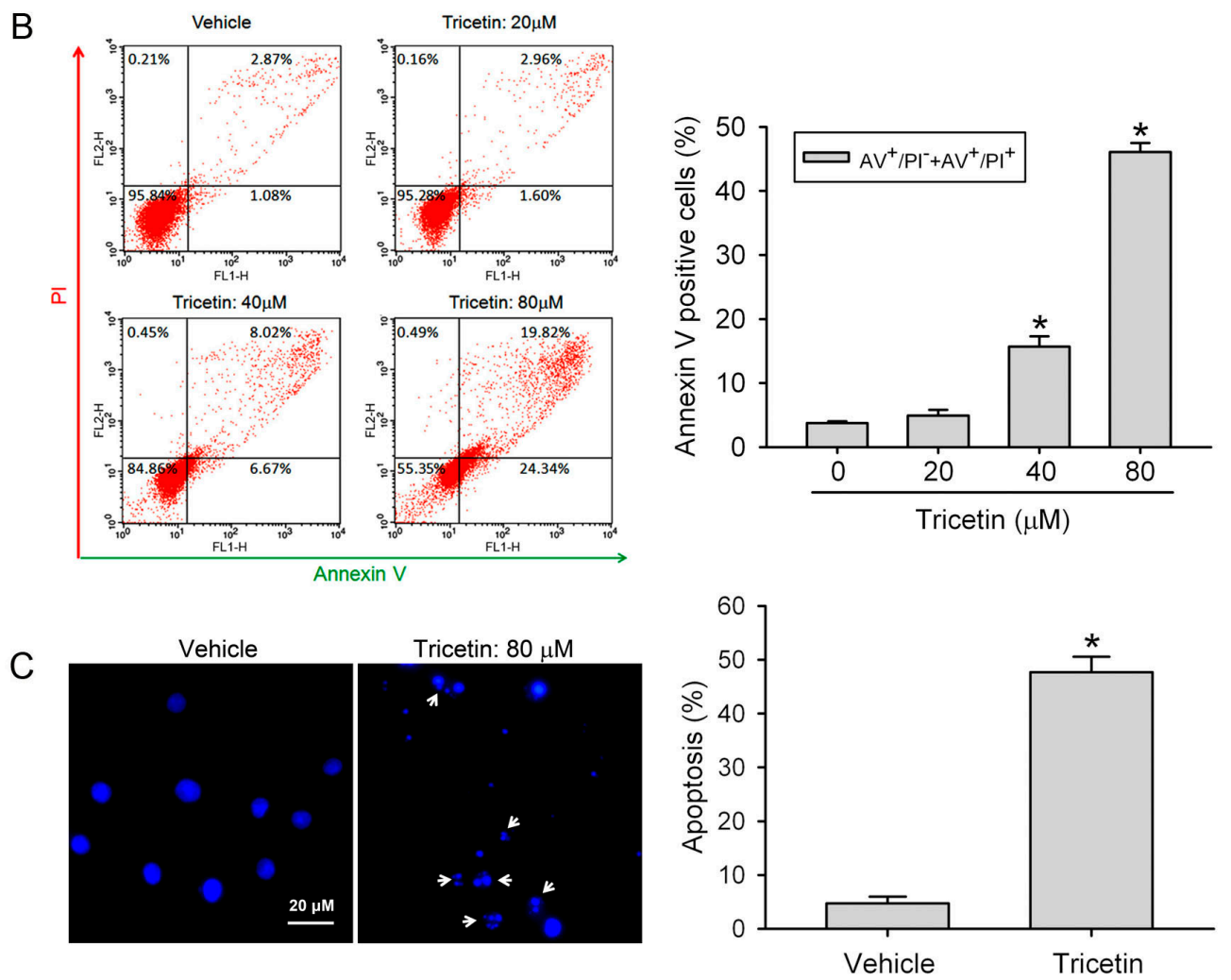

Figure 2. Effect of tricetin on HL-60 cell-cycle regulation and apoptosis. (A) HL-60 cells were treated with different concentrations of tricetin $(0 \sim 80 \mu \mathrm{M})$ for $24 \mathrm{~h}$. The cell-cycle phase distribution and cell death in the sub- $\mathrm{G}_{1}$ phase were analyzed by fluorescence-activated cell sorting (FACS) after propidium iodide (PI) staining. Data are shown as the cell-cycle distribution profile by FACS and the percentage distribution of cells in the sub- $G_{1}, G_{0} / G_{1}, S$, and $G_{2} / M$ phases; (B) HL-60 cells were treated with different concentrations of tricetin $(0 \sim 80 \mu \mathrm{M})$ for $24 \mathrm{~h}$. Quantitative analysis of cell apoptosis by FACS after staining with Annexin-V and PI. In the dot plots, percentages of Annexin- $\mathrm{V}^{+} / \mathrm{PI}^{-}$(cells in early apoptosis, bottom right quadrant) and Annexin- $\mathrm{V}^{+} / \mathrm{PI}^{+}$(cells in late apoptosis, top right quadrant) are shown (C) HL-60 cells were treated with $80 \mu \mathrm{M}$ tricetin for $24 \mathrm{~h}$ and analyzed by fluorescence microscopy after $4^{\prime}, 6$-diamidino-2-phenylindole (DAPI) staining. White arrows indicate apoptotic HL-60 cells. Percentage of apoptotic cells expresses ratio of apoptotic cells to the total cell number. For each sample 200 cells were assessed. Data are expressed as the mean $\pm \mathrm{SE}$ of three independent experiments. ${ }^{*} p<0.05$, compared to the vehicle group. 


\subsection{Tricetin Induces Caspase-Dependent Apoptotic Cell Death in HL-60 Cells}

The apoptotic procedure is carried out by a group of the highly conserved caspases, and modulation of the mechanisms of caspase activation and suppression is a key molecular target in chemoprevention, since these procedures lead to apoptosis [20]. To clarify the mechanisms underlying tricetin-induced apoptosis in AML cells, activation of initiator (caspases-9 and -8) and executioner (caspase-3) caspases was detected. Figure 3A shows that exposure of HL-60 cells to tricetin $(80 \mu \mathrm{M})$ for indicated time points caused hydrolysis of procaspases- $8,-9$, and -3 and cleavage of caspase- 3 's substrate, PARP, in time-dependent manners. Moreover, treatment of HL-60 cells with different concentrations $(0 \sim 80 \mu \mathrm{M})$ of tricetin for $8 \mathrm{~h}$ also resulted in concentration-dependent increases in activated caspases-8, -9 , and -3 , and cleaved PARP (Figure 3B,C). We next further investigated whether activation of caspases is necessary for tricetin-induced apoptosis of HL-60 cells by an MTS assay using specific inhibitors that respectively inhibit caspase-9 (Z-LEHD-FMK), caspase-8 (Z-IETD-FMK), or a broad-spectrum caspase (Z-VAD-FMK). As shown in Figure 3D, all caspase inhibitors significantly attenuated $40 \mu \mathrm{M}$ tricetin-induced inhibition of proliferation. Taken together, the results indicated that tricetin induced rapid and time- and concentration-dependent apoptosis in a caspase-dependent pathway.

A

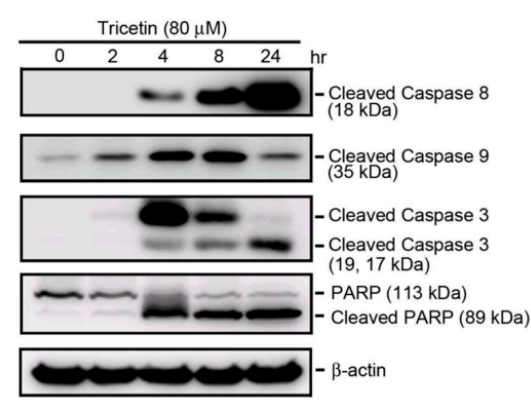

D

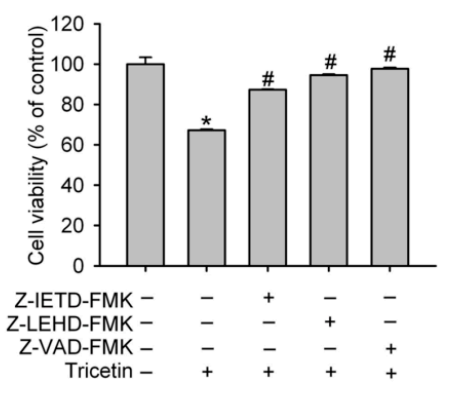

B

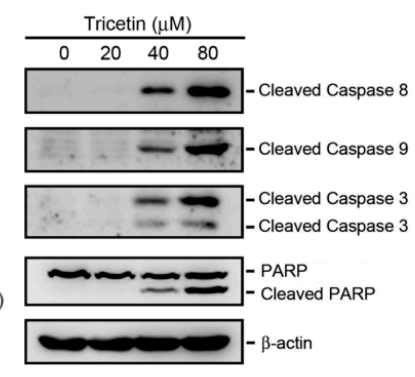

C

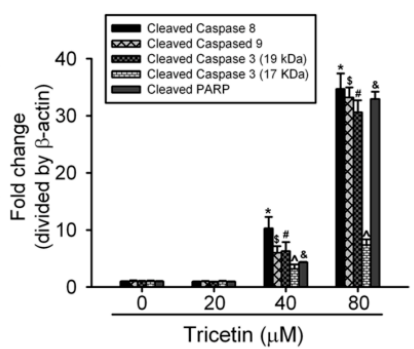

Figure 3. Tricetin induces caspase-dependent apoptotic cell death in HL-60 cells. (A) Expression levels of cleaved caspases-3, -8 , and -9 , and poly(ADP-ribose) polymerase (PARP) were assessed by a Western blot analysis after treatment with $80 \mu \mathrm{M}$ tricetin for indicated time points; (B) Activated caspase-8, -9 , and -3 , and cleaved PARP protein expressions were upregulated in a concentration-dependent fashion after treatment of HL-60 cells with various concentrations of tricetin $(0 \sim 80 \mu \mathrm{M})$ for $8 \mathrm{~h}$; (C) Quantitative results of cleaved caspase- $3,-8$, and -9 , and PARP protein levels, which were adjusted to the $\beta$-actin protein level and expressed as multiples of induction beyond each respective control. Values are presented as the mean \pm SE of three independent experiments. ${ }^{*}, \#, \&,{ }^{\wedge}, \$ p<0.05$, compared to the vehicle control groups; (D) Cells were treated with $40 \mu \mathrm{M}$ tricetin for $24 \mathrm{~h}$ in the presence or absence of $50 \mu \mathrm{M}$ Z-VAD-FMK, Z-LEHD-FMK, or Z-IETD-FMK. Cell proliferation was determined by an MTS assay. Data are presented as the mean \pm SE of three independent experiments performed in triplicate. ${ }^{*} p<0.05$, control vs. tricetin; ${ }^{*} p<0.05$, tricetin vs. Z-VAD-FMK, Z-LEHD-FMK, or Z-IETD-FMK plus tricetin. 


\subsection{Mitogen-Activated Protein Kinases Involved in Tricetin-Regulated Apoptotic Cell Death}

The MAPK signaling pathway, such as JNK1/2 and/or p38 MAPK, was reported to be participated in the caspase-mediated apoptotic effect induced by different traditional Chinese herbs in various cancer types, including AML [21-23]. In contrast, ERK was shown to correlate with the proliferation and drug resistance of hematopoietic cells [24]. Therefore, we determined whether activation of MAPKs was affected in tricetin-treated HL-60 cells, and found that tricetin induced activation of JNK1/2 and ERK1/2, but not p38 MAPK in concentration- and time-dependent manners (Figure 4A-C). Surprisingly, tricetin also induced the formation of cleaved p54 JNK and p52 JNK at $8 \mathrm{~h}$ after the addition of 40 or $80 \mu \mathrm{M}$ tricetin (Figure $4 \mathrm{~A}, \mathrm{~B}$ ). To further investigate relationships among tricetin-induced activation of caspases and MAPKs, HL-60 cells were pretreated with U0126 (an ERK inhibitor) or JNK-IN-8 (a JNK inhibitor) for $1 \mathrm{~h}$, treated with $40 \mu \mathrm{M}$ tricetin for another $24 \mathrm{~h}$, and then analyzed by Western blotting. As shown in Figure 4D JNK-IN-8 and U0126 respectively attenuated and increased tricetin-induced caspase- 8 and -3 activation. Moreover, we found that JNK-IN-8 and U0126 also respectively attenuated and enhanced tricetin-induced inhibition of proliferation (Figure 4E). These findings suggest that activation of ERK1/2 and JNK1/2 might play opposite roles in tricetin-mediated caspase activation and cell death in HL-60 cells.

A

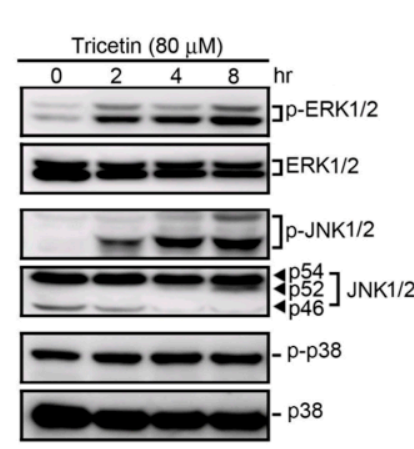

D
B

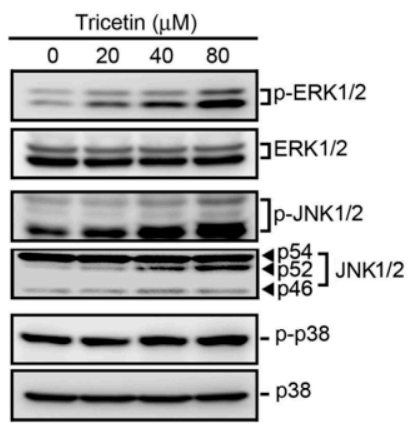

C

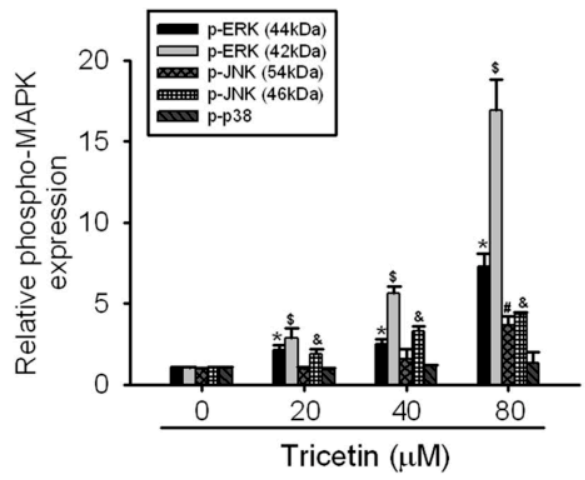

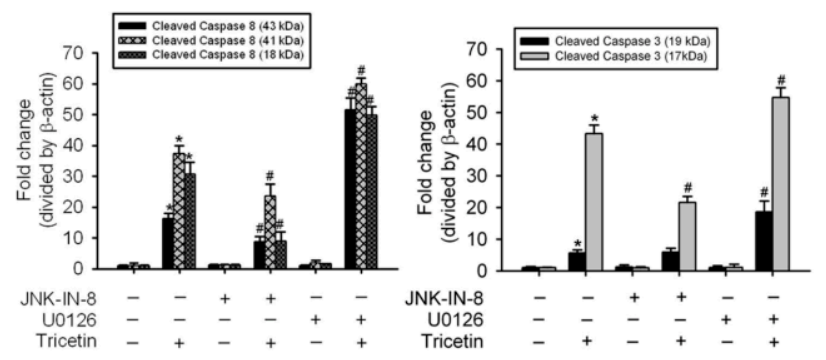

Figure 4. Cont. 
$\mathrm{E}$

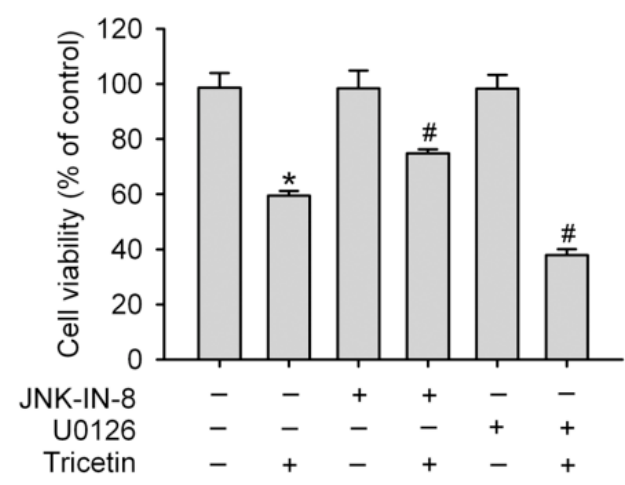

Figure 4. Role of mitogen-activated protein kinases (MAPKs) in tricetin-induced apoptotic cell death in HL-60 cells. (A,B) Phosphorylation levels of extracellular signal-regulated kinase (ERK)1/2, p38, and c-Jun N-terminal kinase (JNK)1/2 were assessed by a Western blot analysis after treatment of HL-60 cells with $80 \mu \mathrm{M}$ tricetin for indicated time points (A) or with various concentrations of tricetin $(0 \sim 80 \mu \mathrm{M})$ for $8 \mathrm{~h}(\mathbf{B}, \mathbf{C})$ Quantitative results of phopho-ERK1/2, p38, and JNK1/2 protein levels, which were adjusted to the total ERK1/2, p38, and JNK1/2 protein levels and expressed as multiples of induction beyond each respective control. Values are presented as the mean \pm SE of three independent experiments. *, \#, \& $\$$ \$ $p<0.05$, compared to the vehicle control groups; (D,E) HL-60 cells were pretreated with or without $5 \mu \mathrm{M}$ U0126 or $1 \mu \mathrm{M}$ JNK-IN-8 for $1 \mathrm{~h}$ followed by tricetin $(40 \mu \mathrm{M})$ treatment for an additional $24 \mathrm{~h}$. Expression levels of cleaved caspases-3, -8 , and cell viability were respectively determined by a Western blot analysis (D, left panel) and a CCK-8 assay (E). Quantitative results of cleaved caspase-3 and -8 protein levels, which were adjusted to the $\beta$-actin protein level and expressed as multiples of induction beyond each respective control (D, right panel). Values represent the mean $\pm \mathrm{SE}$ of three independent experiments. ${ }^{*} p<0.05$, control vs. tricetin; ${ }^{*} p<0.05$, tricetin vs. U0126 or JNK-IN-8 plus tricetin.

\subsection{Tricetin-Induced Intracellular Oxidative Stress as an Initial Signal for JNK-Mediated Apoptosis in HL-60 Cells}

A recent report suggested that JNK activation is associated with ROS-induced apoptosis of chronic myelogenous leukemia cells [25]. In order to test whether tricetin leads to ROS generation in AML cells, HL-60 cells were treated with tricetin for indicated time points, and cellular ROS were monitored with $\mathrm{H}_{2}$ DCFDA, a fluorescent, redox-sensitive dye. Our results showed that compared to the control group, treatment of cells with $80 \mu \mathrm{M}$ tricetin dramatically increased dichlorofluorescein (DCF) fluorescence at 6 and $8 \mathrm{~h}$ after treatment (Figure 5A). To further dissect the correlation between ROS production and JNK activation in tricetin-mediated cell death, the results showed that pretreating HL-60 cells with the antioxidant, NAC, significantly blocked 40 and $80 \mu \mathrm{M}$ tricetin-induced JNK activation and cleavage (Figure 5B) and subsequently reversed tricetin-induced cell death as evidenced from decreases in tricetin-induced PARP cleavage (Figure 5C), procaspase-9 and -3 hydrolysis (Figure S1), and cell proliferation inhibition (Figure 5D). 
A

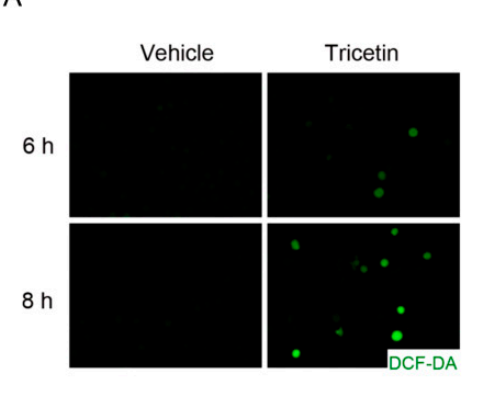

B

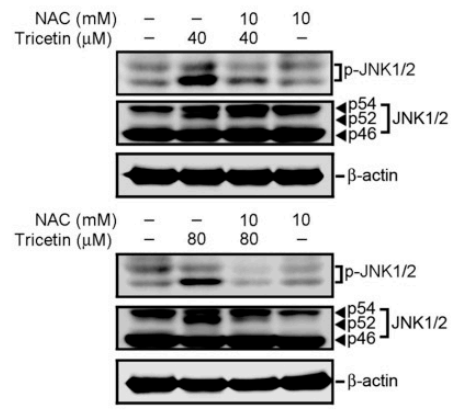

C

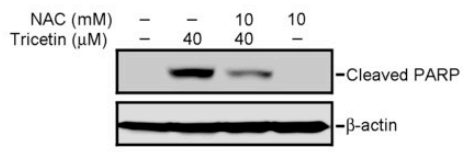

$\mathrm{NAC}(\mathrm{mM}) \quad-\quad-\quad 10 \quad 10$

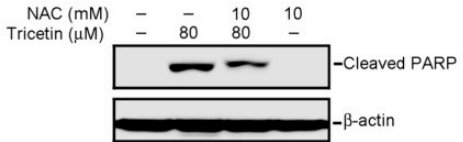

D

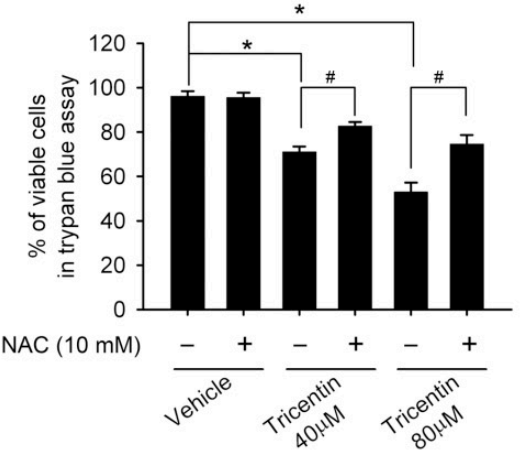

$\mathrm{E}$

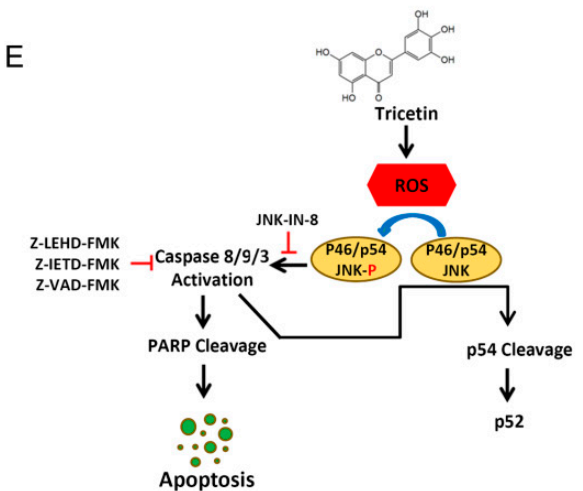

Figure 5. Tricetin-induced intracellular oxidative stress as an initial signal for c-Jun N-terminal kinase (JNK)-mediated apoptosis in HL-60 cells. (A) HL-60 cells were treated with $80 \mu \mathrm{M}$ tricetin for the indicated time, and then the total reactive oxygen species (ROS) level was measured by $\mathrm{H}_{2} \mathrm{DCF}-\mathrm{DA}$ staining under a fluorescence microscope. Original magnification, $200 \times$; (B,C) HL-60 cells were pretreated with or without $10 \mathrm{mM} \mathrm{N}$-acetylcysteine (NAC) for $1 \mathrm{~h}$ followed by treatment with 40 or $80 \mu \mathrm{M}$ tricetin for $8 \mathrm{~h}$; levels of JNK1/2, p-JNK1/2, cleaved poly(ADP ribose) polymerase (PARP), and $\beta$-actin were detected by a Western blot analysis; (D) HL-60 cells were pretreated with or without $10 \mathrm{mM}$ NAC for $1 \mathrm{~h}$ followed by treatment with 40 or $80 \mu \mathrm{M}$ tricetin for $12 \mathrm{~h}$ Trypan blue exclusion assay was used to quantify the cell viability change in each group. Values represent the mean $\pm \mathrm{SE}$ of three independent experiments. ${ }^{*} p<0.05$, control vs. tricetin; ${ }^{\#} p<0.05$, tricetin vs. NAC plus tricetin; (E) Proposed signal transduction pathways by which tricetin induces apoptosis of acute myeloid leukemias (AML) cells. The antileukemic activity of tricetin was attributed to its apoptosis induction by increasing ROS production and further inducing activation of JNK and caspases-8, -9 , and -3 . The p54 JNK cleavage was also induced by tricetin-mediated ROS upregulation. Black arrows indicate induced effects and red t-bar indicate inhibitory effects.

\section{Discussion}

AML is a non-solid tumor with high mortality rates. At present, conventional chemotherapy has favorable outcomes; however, the response is limited by progressive resistance and a number of side effects [2]. There is great interest in therapy with drugs of plant origins, because traditional medicines have less toxicity and fewer side effects [13]. Our current study showed that tricetin, a dietary flavonoid in Myrtaceae pollen and Eucalyptus honey, reduced HL-60 leukemic cell growth through increasing endogenous ROS production, which is the initial signal to activate JNK1/2-mediated cell apoptosis. Therefore, tricetin could have physiologic value taken in a natural food form.

The enhancement of ROS production has long been associated with the apoptotic response induced by several anticancer agents [26]. Targeting ROS levels could be a novel approach for AML treatment since ROS levels are higher in malignant cells than in non-malignant cells [27]. Furthermore, increasing oxidative stress is emerging as a promising therapy for leukemia [28]. For example, our previous study showed that quercetin induced cell death of HL-60 cells in vitro and in vivo through 
induction of intracellular oxidative stress [29]. Moreover, several studies also showed that clinically achievable concentrations $(1 \sim 2 \mu \mathrm{M})$ of a chemotherapeutic drug, arsenic trioxide $\left(\mathrm{As}_{2} \mathrm{O}_{3}\right)$, induced apoptosis through an ROS-dependent pathway in acute promyelocytic leukemia (APL or AML M3) [30]. Accumulation of intracellular ROS by quercetin or $\mathrm{As}_{2} \mathrm{O}_{3}$ led to dissipation of the mitochondrial membrane potential (MMP), release of cytochrome $\mathrm{c}$ from mitochondria, subsequent activation of caspase-9, and ultimately apoptotic cell death [31,32]. Our study showed that tricetin can induce caspase-9-mediated cell death, but the effect of tricetin on the MMP in AML cells will be investigated in our future work. Recently, flavonoids isolated from grape or Citrus paradisi Macfadyen were reported to enhance the antileukemic activity of $\mathrm{As}_{2} \mathrm{O}_{3}[33,34]$. In addition, several mild ROS generators were also reported to facilitate $\mathrm{As}_{2} \mathrm{O}_{3}$-induced apoptosis of different types of cancer cells as well as $\mathrm{As}_{2} \mathrm{O}_{3}$-resistant leukemic cell lines [28]. The therapeutic potential of tricetin combined with $\mathrm{As}_{2} \mathrm{O}_{3}$ in AML treatment will also be further investigated.

Chemotherapeutic resistance and relapse remain major challenges in treating AML. Previous reports indicated that JNK activation is the critical step for the chemotherapy drug, anthracycline, to trigger apoptosis in AML, and a JNK-activation defect confers chemoresistance in AML [18]. Mitochondrial release of ROS upon different apoptotic stimulations can lead to activation of JNK [25,35]. In response to ROS, JNKs induce the phosphorylation and inactivation of antiapoptotic proteins such as B-cell lymphoma 2 (Bcl-2) and B-cell lymphoma-extra large (Bcl-XL) [35]. Previous reports indicated that $\mathrm{Bcl}-2$ and $\mathrm{Bcl}-\mathrm{XL}$ can antagonize ROS generation and protect cells from ROS-mediated apoptosis [36]. In addition, JNK was also reported to modify the composition of the Bcl-2-associated $\mathrm{X}$ (Bax)/Bcl-2 complex through increasing the expression of Bax, leading to formation of Bax homodimers resulting in dissipation of mitochondrial membrane potential [37]. Actually, Hsu et al. have demonstrated that tricetin-induced liver cancer cells apoptosis is associated with Bcl-2 family members-regulated mitochondrial pathway, which is mediated by ROS generation and, subsequently, JNK activation [8]. Our current study demonstrated that tricetin induced leukemic cell death through inducing ROS-mediated JNK activation. The effect of tricetin on Bcl-2 family members and determining whether tricetin can sensitize anthracycline-induced cell death in AML through JNK activity modulation are worthy of evaluating in future work. In addition to JNK activation, we also observed the conversion of p52 from p 54 JNK after tricetin treatment in AML cells. This finding is in line with previous reports in MOLT-4 and U937 leukemia cells which showed X-irradiation or heat treatment can induce caspase-3-mediated cleavage of p54 JNK, and this JNK cleaved form still harbors its kinase activity [38].

In addition to JNK, our study also showed that tricetin can induce ROS-mediated ERK activation in HL-60 cells (Figure S2). ERK activation was reported to be a key pathway that protects cancer cells from apoptosis including in leukemia [39]. Previous reports indicated that ERK1/2 can promote leukemic cell survival by enhancing the activity of antiapoptotic proteins including Bcl-2, Bcl-XL, Mcl-1, inhibitor of apoptosis protein (IAP), and repressing the activity or expression of proapoptotic proteins, such as Bad, Bim, and caspase-9 [39,40]. Recently, evidence has also shown that ERK1/2 can have proapoptotic functions in response to different stimuli such as etoposide, bufalin, shikonin, doxorubicin, and apigenin in different cancer types [40]. Although our present results indicated that tricetin $(40$ and $80 \mu \mathrm{M})$ can induce apoptosis of HL-60 cells, results showed that ERK can also be activated instead of inhibited by higher concentrations (40 and $80 \mu \mathrm{M})$ of tricetin. Moreover, inhibition of the ERK pathway by a specific inhibitor further enhanced the apoptosis-inducing effect of tricetin in AML cells. Consistent results from previous studies also indicated that an ERK inhibitor enhances docetaxel- and DAPT-induced apoptosis in androgen-independent prostate cancer and gastric cancer, respectively [41,42]. Taken together, we propose that ERK activation induced by higher concentrations of tricetin may have been due to a cell-derived protective effect against the toxic effects of tricetin. According to these findings, we suggest that a combination of tricetin and an ERK inhibitor may be a good strategy for preventing the growth of AML cells. 
In addition to MAPKs, a breast cancer resistance protein (BCRP/ABCG2) was reported to be overexpressed by stem cells in leukemias, potentially contributing to their resistance to eradication by chemotherapy or targeted therapies and to be associated with a poor response to conventional chemotherapy and increased risk of relapse [43]. Recently, tricetin was identified as a novel flavonoid ABCG2 inhibitor [44], but the effect of tricetin on the stemness of leukemia should be further investigated.

\section{Materials and Methods}

\subsection{Materials}

Tricetin was purchased from Extrasynthese (Genay, France). An 80-mM stock solution of tricetin was made in dimethyl sulfoxide (DMSO) (Sigma-Aldrich, St. Louis, MO, USA) and stored at $-20{ }^{\circ} \mathrm{C}$. The final concentration of DMSO for all treatments was $<0.5 \% .2^{\prime}, 7^{\prime}$-Dichlorofluorescein diacetate (DCFDA), N-acetylcysteine (NAC), z-IETD-FMK (a caspase-8 inhibitor), zLEHD-FMK (a caspase-9 inhibitor), and a general inhibitor of caspases (zVAD-FMK) were purchased from Sigma-Aldrich. Antibodies against poly(ADP-ribose) polymerase (PARP), phosphorylated (p)-c-Jun N-terminal kinase (JNK), JNK1/2, p-extracellular signal-regulated kinase (ERK)1/2, caspase-9, caspase-3, and caspase-8 were purchased from Cell Signaling Technology (Beverly, MA, USA). Anti-p-p38, p38, and $\beta$-actin antibodies were obtained from BD Biosciences (San Jose, CA, USA).

\subsection{Cell Culture}

The human MV4-11, HL-60, U937, and THP-1 AML cell lines were purchased from American Type Culture Collection (Manassas, VA, USA). All cell lines were cultured in RPMI 1640 medium supplemented with $10 \%$ heat-inactivated fetal bovine serum (FBS; Gibco, Grand Island, NY, USA), 0.1 mM nonessential amino acids, $2 \mathrm{mM}$ L-glutamine, $100 \mathrm{U} / \mathrm{mL}$ penicillin, and $100 \mu \mathrm{g} / \mathrm{mL}$ streptomycin.

\subsection{In Vitro Cytotoxicity Assay}

Four AML cells (MV4-11, HL-60, U937, and THP-1) were cultured in 96-well plates containing complete media and treated with different concentrations of tricetin $(0,20,40,80$, and $160 \mu \mathrm{M})$ for $24 \mathrm{~h}$, and cell viabilities were examined using a Cell Counting Kit-8 (CCK-8) (Sigma-Aldrich) or MTS (Promega, Madison, WI, USA) assay. The absorbance (A) was read at $450 \mathrm{~nm}$ (CCK-8 assay) or $490 \mathrm{~nm}$ (MTS assay) using an enzyme-linked immunosorbent assay (ELISA) reader (MQX200; Bio-Tek Instruments, Winooski, VT, USA). The cell viability rate (multiple) was analyzed by the formula: $\mathrm{A}_{450}$ or 490 , tricetin $/ \mathrm{A}_{450}$ or 490 , vehicle.

\subsection{In Vitro Cell Viability Assay}

The effect of tricetin on the viability of HL-60 cells was determined by a trypan blue dye exclusion assay. Briefly, the HL-60 cells were plated at a density of $5 \times 10^{3}$ in 96-well plates containing complete media and treated with tricetin, or tricetin combined NAC. After incubation for indicated time points, cells were collected and an aliquot of cell suspension was mixed with an equal volume of trypan blue and cells were counted under the microscope.

\subsection{Flow Cytometric Analysis of DNA Contents}

HL-60 cells $\left(2 \times 10^{6} / \mathrm{mL}\right)$ were treated with vehicle or tricetin $(0,20,40$, and $80 \mu \mathrm{M})$ for $24 \mathrm{~h}$ and then cells were collected and fixed by $70 \%$ ethanol. Next, cells were incubated with propidium iodide (PI) buffer $(4 \mu \mathrm{g} / \mathrm{mL}$ PI, $0.5 \mathrm{mg} / \mathrm{mL}$ RNase A, and 1\% Triton X-100 in phosphate-buffered saline (PBS)) for $30 \mathrm{~min}$ at $37^{\circ} \mathrm{C}$ in the dark followed by filtration through a $40-\mu \mathrm{m}$ nylon filter (Falcon, San Jose, CA, USA). The cell cycle distribution was analyzed for $10^{4}$ collected cells by a FACS Vantage flow cytometer that uses the Cellquest acquisition and analysis program (Becton-Dickinson FACS Calibur, 
San Jose, CA, USA). The proportion of nuclei in each phase of the cell cycle was determined, and apoptotic cells with hypodiploid DNA peak were catched in the sub- $\mathrm{G}_{1}$ region.

\subsection{4,6-Diamidino-2-phenylindole (DAPI) Staining}

Morphological changes in the nuclear chromatin of cells undergoing apoptosis were visualized following DNA staining using the fluorescent dye 4,6-diamidino-2-phenylindole (DAPI, Sigma). After incubation for $24 \mathrm{~h}$ with tricetin, HL-60 cells were fixed with methanol, stained with the DAPI solution for $10 \mathrm{~min}$ at room temperature, and examined under a fluorescence microscope. Apoptotic cells exhibited morphological features of apoptosis including nuclear fragmentation and chromatin condensation. The percentage of apoptotic cells were calculated as the ratio of apoptotic cells to total cells counted.

\subsection{Apoptosis Assays}

Apoptotic cell death was determined by Annexin-V-fluorescein isothiocyanate (FITC)/PI double staining, using an FITC-labeled Annexin-V/PI Apoptosis Detection kit (BD Biosciences, San Jose, CA, USA) following the manufacturer's guidelines. HL-60 cells were exposed to tricetin at the indicated concentration for $24 \mathrm{~h}$, cells were then washed with PBS following trypsinization, resuspended in $100 \mu \mathrm{L}$ of binding buffer (10 mM HEPES/ NaOH, $140 \mathrm{mM} \mathrm{NaCl}$, and $2.5 \mathrm{mM} \mathrm{CaCl} 2$ at $\mathrm{pH} 7.4)$ and stained with $5 \mu \mathrm{L}$ of FITC-conjugated Annexin-V and $5 \mu \mathrm{L}$ of PI $(50 \mu \mathrm{g} / \mathrm{mL})$ for $30 \mathrm{~min}$ at room temperature, and then $400 \mu \mathrm{L}$ of binding buffer was added. Apoptotic cells were analyzed by flow cytometry with a FACScan system flow cytometric analysis. Data acquisition and analysis were performed in a Becton-Dickinson FACSCalibur flow cytometer using CellQuest software (BD Biosciences).

\subsection{Preparation of Total Cell Extracts and Western Blot Analysis}

Cell lysates were prepared as previously described. The protein content was determined with the Bio-Rad protein assay reagent using bovine serum albumin as a standard. Equal amounts of protein extracts $(10 \sim 50 \mu \mathrm{g})$ were boiled in Laemmli sample buffer, separated on sodium dodecylsulfate (SDS) polyacrylamide gels, electrophoretically transferred to polyvinylidene fluoride membranes (Millipore, Belford, MA, USA) and incubated with the indicated primary antibodies at $4{ }^{\circ} \mathrm{C}$ overnight. Blots were then further incubated with a horseradish peroxidase (HRP)-conjugated secondary antibodies for $1 \mathrm{~h}$ at room temperature. Signals were detected through enhanced chemiluminescence (ECL) Western blotting detection reagents (Millipore, Billerica, MA, USA).

\subsection{Measurement of ROS Production}

HL-60 cells were treated with tricetin $(80 \mu \mathrm{M})$ for 6 and $8 \mathrm{~h}$; then ROS production was detected by staining with an ROS probe ( $5 \mu \mathrm{M}$ DCFDA) in RPMI 1640 medium for $30 \mathrm{~min}$. Cells were then washed with PBS or medium and ROS production of DCFDA-preloaded cells were captured with a fluorescence microscope (Nikon Eclipse TE 300, Tokyo, Japan).

\subsection{Statistical Analysis}

Data points represent the mean \pm standard error (SE). We performed statistical analyses with Student $t$ test was used to compare data between two groups. $p$ values of $<0.05$ were considered statistically significant.

\section{Conclusions}

In conclusion, we first report that tricetin possesses an antileukemic effect on AML cells, and that phenomenon stems from induction of intracellular oxidative stress, which initiates a signal leading to activation of JNK and induces caspase-dependent apoptosis; the mechanism is schematically illustrated 
in Figure 5E. In addition, we also found that a combination of tricetin and an ERK inhibitor presented a better apoptosis-inducing effect on AML cells than tricetin treatment alone. Our discovery of this novel mechanism of tricetin not only gives further insights into its anticancer potential against hematological malignancies, but also contributes to developing tricetin as a chemopreventive or chemotherapeutic agent in managing human AML.

Supplementary Materials: Supplementary materials can be found at www.mdpi.com/1422-0067/18/8/1667/s1.

Acknowledgments: This study was supported by grant numbers 106 swf03 from Taipei Medical University-Wan Fang Hospital and CSH-2015-C-002 from Chung Shan Medical University Hospital.

Author Contributions: Ming-Hsien Chien, Jyh-Ming Chow, Pei-Ching Hsiao, and Shun-Fa Yang conceived and designed the experiments, contributed materials, and analyzed the data; Wei-Jiunn Lee, Hui-Yu Chen, and Peng Tan performed the experiments; Yu-Ching Wen contributed analytical tools; Yung-Wei Lin, Ming-Hsien Chien, and Shun-Fa Yang contributed reagents and wrote the paper.

Conflicts of Interest: The authors declare no conflict of interest.

\section{Abbreviations}

$\begin{array}{ll}\text { AML } & \text { Acute myeloid leukemia } \\ \text { DCF } & \text { Dichlorofluorescein } \\ \text { DMSO } & \text { Dimethyl sulfoxide } \\ \text { ERK } & \text { Extracellular signal-regulated kinase } \\ \text { JNK } & \text { c-Jun N-terminal kinase } \\ \text { NAC } & \text { N-Acetylcysteine } \\ \text { PARP } & \text { Poly(ADP-ribose) polymerase } \\ \text { PI } & \text { Propidium iodide } \\ \text { PS } & \text { Phosphatidylserine } \\ \text { ROS } & \text { Reactive oxygen species }\end{array}$

\section{References}

1. Burnett, A.K.; Hills, R.K.; Milligan, D.W.; Goldstone, A.H.; Prentice, A.G.; McMullin, M.F.; Duncombe, A.; Gibson, B.; Wheatley, K. Attempts to optimize induction and consolidation treatment in acute myeloid leukemia: Results of the MRC AML12 trial. J. Clin. Oncol. 2010, 28, 586-595. [CrossRef] [PubMed]

2. Tallman, M.S.; Gilliland, D.G.; Rowe, J.M. Drug therapy for acute myeloid leukemia. Blood 2005, 106, 1154-1163. [CrossRef] [PubMed]

3. Estey, E.; Dohner, H. Acute myeloid leukaemia. Lancet 2006, 368, 1894-1907. [CrossRef]

4. Shanafelt, T.D.; Lee, Y.K.; Call, T.G.; Nowakowski, G.S.; Dingli, D.; Zent, C.S.; Kay, N.E. Clinical effects of oral green tea extracts in four patients with low grade B-cell malignancies. Leuk. Res. 2006, 30, 707-712. [CrossRef] [PubMed]

5. Lucas, D.M.; Still, P.C.; Perez, L.B.; Grever, M.R.; Kinghorn, A.D. Potential of plant-derived natural products in the treatment of leukemia and lymphoma. Curr. Drug Targets 2010, 11, 812-822. [CrossRef] [PubMed]

6. Geraets, L.; Moonen, H.J.; Brauers, K.; Wouters, E.F.; Bast, A.; Hageman, G.J. Dietary flavones and flavonoles are inhibitors of poly(ADP-ribose)polymerase-1 in pulmonary epithelial cells. J. Nutr. 2007, 137, 2190-2195. [PubMed]

7. Hsu, Y.L.; Uen, Y.H.; Chen, Y.; Liang, H.L.; Kuo, P.L. Tricetin, a dietary flavonoid, inhibits proliferation of human breast adenocarcinoma MCF-7 cells by blocking cell cycle progression and inducing apoptosis. J. Agric. Food Chem. 2009, 57, 8688-8695. [CrossRef] [PubMed]

8. Hsu, Y.L.; Hou, M.F.; Tsai, E.M.; Kuo, P.L. Tricetin, a dietary flavonoid, induces apoptosis through the reactive oxygen species/c-Jun $\mathrm{NH}_{2}$-terminal kinase pathway in human liver cancer cells. J. Agric. Food Chem. 2010, 58, 12547-12556. [CrossRef] [PubMed]

9. Hung, J.Y.; Chang, W.A.; Tsai, Y.M.; Hsu, Y.L.; Chiang, H.H.; Chou, S.H.; Huang, M.S.; Kuo, P.L. Tricetin, a dietary flavonoid, suppresses benzo(a)pyreneinduced human nonsmall cell lung cancer bone metastasis. Int. J. Oncol. 2015, 46, 1985-1993. [PubMed] 
10. Chang, P.Y.; Hsieh, M.J.; Hsieh, Y.S.; Chen, P.N.; Yang, J.S.; Lo, F.C.; Yang, S.F.; Lu, K.H. Tricetin inhibits human osteosarcoma cells metastasis by transcriptionally repressing MMP-9 via p38 and Akt pathways. Environ. Toxicol. 2016. [CrossRef] [PubMed]

11. Chao, R.; Chow, J.M.; Hsieh, Y.H.; Chen, C.K.; Lee, W.J.; Hsieh, F.K.; Yu, N.Y.; Chou, M.C.; Cheng, C.W.; Yang, S.F.; et al. Tricetin suppresses the migration/invasion of human glioblastoma multiforme cells by inhibiting matrix metalloproteinase-2 through modulation of the expression and transcriptional activity of specificity protein 1. Expert Opin. Ther. Targets 2015, 19, 1293-1306. [CrossRef] [PubMed]

12. Elmore, S. Apoptosis: A review of programmed cell death. Toxicol. Pathol. 2007, 35, 495-516. [CrossRef] [PubMed]

13. Safarzadeh, E.; Sandoghchian Shotorbani, S.; Baradaran, B. Herbal medicine as inducers of apoptosis in cancer treatment. Adv. Pharm. Bull. 2014, 4, 421-427. [PubMed]

14. Dhillon, A.S.; Hagan, S.; Rath, O.; Kolch, W. MAP kinase signalling pathways in cancer. Oncogene 2007, 26, 3279-3290. [CrossRef] [PubMed]

15. Fan, M.; Chambers, T.C. Role of mitogen-activated protein kinases in the response of tumor cells to chemotherapy. Drug Resist. Updates 2001, 4, 253-267. [CrossRef] [PubMed]

16. Li, F.; Meng, L.; Zhou, J.; Xing, H.; Wang, S.; Xu, G.; Zhu, H.; Wang, B.; Chen, G.; Lu, Y.P.; et al. Reversing chemoresistance in cisplatin-resistant human ovarian cancer cells: A role of c-Jun $\mathrm{NH}_{2}$-terminal kinase 1. Biochem. Biophys. Res. Commun. 2005, 335, 1070-1077. [CrossRef] [PubMed]

17. Yan, F.; Wang, X.M.; Liu, Z.C.; Pan, C.; Yuan, S.B.; Ma, Q.M. JNK1, JNK2, and JNK3 are involved in P-glycoprotein-mediated multidrug resistance of hepatocellular carcinoma cells. Hepatobiliary Pancreat. Dis. Int. 2010, 9, 287-295. [PubMed]

18. Lagadinou, E.D.; Ziros, P.G.; Tsopra, O.A.; Dimas, K.; Kokkinou, D.; Thanopoulou, E.; Karakantza, M.; Pantazis, P.; Spyridonidis, A.; Zoumbos, N.C. c-Jun N-terminal kinase activation failure is a new mechanism of anthracycline resistance in acute myeloid leukemia. Leukemia 2008, 22, 1899-1908. [CrossRef] [PubMed]

19. Ouyang, L.; Shi, Z.; Zhao, S.; Wang, F.T.; Zhou, T.T.; Liu, B.; Bao, J.K. Programmed cell death pathways in cancer: A review of apoptosis, autophagy and programmed necrosis. Cell Prolif. 2012, 45, 487-498. [CrossRef] [PubMed]

20. Khan, N.; Afaq, F.; Mukhtar, H. Apoptosis by dietary factors: The suicide solution for delaying cancer growth. Carcinogenesis 2007, 28, 233-239. [CrossRef] [PubMed]

21. Chinen, T.; Nagumo, Y.; Watanabe, T.; Imaizumi, T.; Shibuya, M.; Kataoka, T.; Kanoh, N.; Iwabuchi, Y.; Usui, T. Irciniastatin A induces JNK activation that is involved in caspase-8-dependent apoptosis via the mitochondrial pathway. Toxicol. Lett. 2010, 199, 341-346. [CrossRef] [PubMed]

22. Hsiao, P.C.; Hsieh, Y.H.; Chow, J.M.; Yang, S.F.; Hsiao, M.; Hua, K.T.; Lin, C.H.; Chen, H.Y.; Chien, M.H. Hispolon induces apoptosis through JNK1/2-mediated activation of a caspase-8, -9, and -3-dependent pathway in acute myeloid leukemia (AML) cells and inhibits AML xenograft tumor growth in vivo. J. Agric. Food Chem. 2013, 61, 10063-10073. [CrossRef] [PubMed]

23. Hsiao, P.C.; Lee, W.J.; Yang, S.F.; Tan, P.; Chen, H.Y.; Lee, L.M.; Chang, J.L.; Lai, G.M.; Chow, J.M.; Chien, M.H. Nobiletin suppresses the proliferation and induces apoptosis involving MAPKs and caspase-8/-9/-3 signals in human acute myeloid leukemia cells. Tumour Biol. 2014, 35, 11903-11911. [CrossRef] [PubMed]

24. McCubrey, J.A.; Steelman, L.S.; Chappell, W.H.; Abrams, S.L.; Wong, E.W.; Chang, F.; Lehmann, B.; Terrian, D.M.; Milella, M.; Tafuri, A.; et al. Roles of the Raf/MEK/ERK pathway in cell growth, malignant transformation and drug resistance. Biochim. Biophys. Acta 2007, 1773, 1263-1284. [CrossRef] [PubMed]

25. Mao, X.; Yu, C.R.; Li, W.H.; Li, W.X. Induction of apoptosis by shikonin through a ROS/JNK-mediated process in Bcr/Abl-positive chronic myelogenous leukemia (CML) cells. Cell Res. 2008, 18, 879-888. [CrossRef] [PubMed]

26. Brodska, B.; Holoubek, A. Generation of reactive oxygen species during apoptosis induced by DNA-damaging agents and/or histone deacetylase inhibitors. Oxid. Med. Cell. Longev. 2011, 2011, 253529. [CrossRef] [PubMed]

27. Zhou, Y.; Hileman, E.O.; Plunkett, W.; Keating, M.J.; Huang, P. Free radical stress in chronic lymphocytic leukemia cells and its role in cellular sensitivity to ROS-generating anticancer agents. Blood 2003, 101, 4098-4104. [CrossRef] [PubMed]

28. Lau, A.T.; Wang, Y.; Chiu, J.F. Reactive oxygen species: Current knowledge and applications in cancer research and therapeutic. J. Cell. Biochem. 2008, 104, 657-667. [CrossRef] [PubMed] 
29. Lee, W.J.; Hsiao, M.; Chang, J.L.; Yang, S.F.; Tseng, T.H.; Cheng, C.W.; Chow, J.M.; Lin, K.H.; Lin, Y.W.; Liu, C.C.; et al. Quercetin induces mitochondrial-derived apoptosis via reactive oxygen species-mediated ERK activation in HL-60 leukemia cells and xenograft. Arch. Toxicol. 2015, 89, 1103-1117. [CrossRef] [PubMed]

30. Alimoghaddam, K. A review of arsenic trioxide and acute promyelocytic leukemia. Int. J. Hematol. Oncol. Stem Cell Res. 2014, 8, 44-54. [PubMed]

31. Yedjou, C.; Tchounwou, P.; Jenkins, J.; McMurray, R. Basic mechanisms of arsenic trioxide (ATO)-induced apoptosis in human leukemia (HL-60) cells. J. Hematol. Oncol. 2010, 3, 28. [CrossRef] [PubMed]

32. Baysan, A.; Yel, L.; Gollapudi, S.; Su, H.; Gupta, S. Arsenic trioxide induces apoptosis via the mitochondrial pathway by upregulating the expression of Bax and Bim in human B cells. Int. J. Oncol. 2007, 30, 313-318. [PubMed]

33. Wang, B.; Lin, S.Y.; Shen, Y.Y.; Wu, L.Q.; Chen, Z.Z.; Li, J.; Chen, Z.; Qian, W.B.; Jiang, J.P. Pure total flavonoids from Citrus paradisi Macfadyen act synergistically with arsenic trioxide in inducing apoptosis of Kasumi-1 leukemia cells in vitro. J. Zhejiang Univ. Sci. B 2015, 16, 580-585. [CrossRef] [PubMed]

34. Fan, Y.; Chen, M.; Meng, J.; Yu, L.; Tu, Y.; Wan, L.; Fang, K.; Zhu, W. Arsenic trioxide and resveratrol show synergistic anti-leukemia activity and neutralized cardiotoxicity. PLoS ONE 2014, 9, e105890. [CrossRef] [PubMed]

35. Cadenas, E. Mitochondrial free radical production and cell signaling. Mol. Asp. Med. 2004, 25, 17-26. [CrossRef] [PubMed]

36. Gottlieb, E.; Vander Heiden, M.G.; Thompson, C.B. Bcl-x(L) prevents the initial decrease in mitochondrial membrane potential and subsequent reactive oxygen species production during tumor necrosis factor alpha-induced apoptosis. Mol. Cell. Biol. 2000, 20, 5680-5689. [CrossRef] [PubMed]

37. Shim, H.Y.; Park, J.H.; Paik, H.D.; Nah, S.Y.; Kim, D.S.; Han, Y.S. Acacetin-induced apoptosis of human breast cancer MCF-7 cells involves caspase cascade, mitochondria-mediated death signaling and SAPK/JNK1/2-c-Jun activation. Mol. Cells 2007, 24, 95-104. [PubMed]

38. Enomoto, A.; Suzuki, N.; Morita, A.; Ito, M.; Liu, C.Q.; Matsumoto, Y.; Yoshioka, K.; Shiba, T.; Hosoi, Y. Caspase-mediated cleavage of JNK during stress-induced apoptosis. Biochem. Biophys. Res. Commun. 2003, 306, 837-842. [CrossRef]

39. Steelman, L.S.; Franklin, R.A.; Abrams, S.L.; Chappell, W.; Kempf, C.R.; Basecke, J.; Stivala, F.; Donia, M.; Fagone, P.; Nicoletti, F.; et al. Roles of the Ras/Raf/MEK/ERK pathway in leukemia therapy. Leukemia 2011, 25, 1080-1094. [CrossRef] [PubMed]

40. Cagnol, S.; Chambard, J.C. ERK and cell death: Mechanisms of ERK-induced cell death-Apoptosis, autophagy and senescence. FEBS J. 2010, 277, 2-21. [CrossRef] [PubMed]

41. Zelivianski, S.; Spellman, M.; Kellerman, M.; Kakitelashvilli, V.; Zhou, X.W.; Lugo, E.; Lee, M.S.; Taylor, R.; Davis, T.L.; Hauke, R.; et al. ERK inhibitor PD98059 enhances docetaxel-induced apoptosis of androgen-independent human prostate cancer cells. Int. J. Cancer 2003, 107, 478-485. [CrossRef] [PubMed]

42. Yao, J.; Qian, C.; Shu, T.; Zhang, X.; Zhao, Z.; Liang, Y. Combination treatment of PD98059 and DAPT in gastric cancer through induction of apoptosis and downregulation of WNT/ $\beta$-catenin. Cancer Biol. Ther. 2013, 14, 833-839. [CrossRef] [PubMed]

43. Natarajan, K.; Xie, Y.; Baer, M.R.; Ross, D.D. Role of breast cancer resistance protein (BCRP/ABCG2) in cancer drug resistance. Biochem. Pharmacol. 2012, 83, 1084-1103. [CrossRef] [PubMed]

44. Tan, K.W.; Li, Y.; Paxton, J.W.; Birch, N.P.; Scheepens, A. Identification of novel dietary phytochemicals inhibiting the efflux transporter breast cancer resistance protein (BCRP/ABCG2). Food Chem. 2013, 138, 2267-2274. [CrossRef] [PubMed]

(C) 2017 by the authors. Licensee MDPI, Basel, Switzerland. This article is an open access article distributed under the terms and conditions of the Creative Commons Attribution (CC BY) license (http:// creativecommons.org/licenses/by/4.0/). 